\title{
Low-Enthalpy Geothermal Springs for Power Generation-An Alternative Approach
}

\author{
L. M. Amoo \\ Stevens Institute of Technology, Hoboken, New Jersey, USA \\ Email:oamoo@alumni.stevens.edu
}

How to cite this paper: Amoo, L.M. (2019) Low-Enthalpy Geothermal Springs for Power Generation-An Alternative Approach. Open Access Library Journal, 6: e5866. https://doi.org/10.4236/oalib.1105866

Received: October 17, 2019

Accepted: November 17, 2019

Published: November 20, 2019

Copyright $\odot 2019$ by author(s) and Open Access Library Inc.

This work is licensed under the Creative Commons Attribution International License (CC BY 4.0).

http://creativecommons.org/licenses/by/4.0/

\begin{abstract}
The Earth is under increasing stress owing to carbon emissions. Clean energy forms constitute an area of increasing technological interest. Geothermal energy is a clean alternative energy form that can be harnessed from the Earth's core. The use of geothermal energy resources is gaining substantial interest in many countries, as an integral part of $21^{\text {st }}$ century clean energy solutions and meeting stringent emission requirements. The objective of this research is to investigate an alternative approach to clean and renewable geothermal energy utilization through geothermal ground water pressure applied within a water turbine. The groundwater pressure from the candidate geothermal sites considered is applied to drive a water turbine for the generation of electrical energy. The geothermal candidate sites are low-temperature (i.e. $<60^{\circ} \mathrm{C}$ ) geothermal springs, where it is not beneficial to apply low temperatures in a Rankine cycle steam turbine due to the low enthalpy. Simple calculations are conducted to estimate the electrical energy output of each candidate site. This may technically be regarded as a thermodynamic problem, albeit one that does not require full thermodynamic cycle analysis. The results of the simple non-rigorous analysis indicate that the electrical energy generation potential is greater when using geothermal water pressure $\left(2.5 \mathrm{MW}_{\mathrm{e}}\right)$ than when using low geothermal temperature $\left(0.005 \mathrm{MW}_{\mathrm{e}}\right)$.
\end{abstract}

\section{Subject Areas}

Electric Engineering

\section{Keywords}

Low-Enthalpy Geothermal Energy, Renewable Energy, Electrical Energy Generation, Water Turbine

\section{Introduction}

Sub-Saharan Africa (SSA), is one of the numerous regions of the world, with a 
particularly high projected increase in energy demand. The deployment of alternative and clean energy forms will undoubtedly enhance socio-economic conditions, and over time, climate changes will also be reduced (that is, by preventing anthropogenic greenhouse gases from fossil fuels and the resulting warming).

According to World Bank estimates, countries in SSA experience annual electrical power outages ranging from $50 \mathrm{~h}$ to $4600 \mathrm{~h}$, which can be juxtaposed with the $8760 \mathrm{~h}$ available in a year. As a result, the majority of the populace rely on diesel-or-petrol generated internal combustion engine (ICE) to meet electrical energy needs. However, the cost of using such generators is significant. In the most populous nation in Africa, namely Nigeria, the mean net cost of electrical energy from ICE generators is approximately $\$ 14$ billion annually, whereas in a smaller nation like Senegal it is approximately $\$ 4$ million annually. These estimates are also higher than the cost of grid electricity. Also, in Nigeria, the unreliable electricity, costs the economy over $\$ 25$ billion annually. The broader implications thereof include pollutant emissions that endanger both the environment and human health [1] [2].

One of the many means of addressing the electrical energy deficit and improving the environment in developing nations may be through the use of renewable energy forms, such as geothermal energy. Diversifying energy resource generation will enhance energy security and help build an all-encompassing base in the mid-to-long-term energy situation. For example, according to the US Energy Information Administration, as of 2018, carbon emissions decreased by $28 \%$ since 2005 in the US, owing in part to slower electrical energy demand growth, as well as an increase in wind and solar energy for electricity generation.

Geothermal energy is a constant form of renewable energy, which is not subjected to the vagaries of weather and seasons, compared to wind and solar energy. It is a stable, low-carbon energy resource, often with a high capacity factor. In principle, the potential offered by geothermal energy is tremendous. The Earth's interior has an abundant store of thermal energy, mostly owing to radioactivity or the radioactive decaying of elements in the Earth's crust. Hot geothermal springs are produced by the emergence of geothermally-heated groundwater from the Earth's crust. Such springs are formed when water interacts with heated porous rocks. Water percolates into the crust and is heated as it encounters hot rocks. More precisely, as cracks extend downwards towards the hot temperatures of the mantle, and water equally seeps down, it is heated and forced back up under pressure, thereby creating a hot spring bubbling at the surface. Notably, convection heat transfer also plays a significant role in this process. Geothermal springs are in essence a useful learning place for researchers. It is generally agreed that not only the resource temperature, but also, its pressure is a key indicator of its potential.

At present, geothermal energy is undergoing a resurgence regarding interest in fully exploiting the resource as a clean energy form. A total of ten nations, namely the US, Japan, Iceland, New Zealand, Italy, Mexico, Indonesia, Kenya, 
Turkey, and the Philippines have established geothermal plants in various capacities. Moreover, eight nations, namely Germany, Portugal, Russia, El Salvador, Costa Rica, New Guinea, and Nicaragua have geothermal plants with various capacities under development. For example, in the Philippines geothermal energy contributes $18 \%$ of electrical power, in Iceland, geothermal energy contributes $27 \%$ of electrical power while, in El Salvador, it contributes 26\% [3]. However, the global development of geothermal energy in meeting the sustainability objectives of the International Energy Administration's (IEA) in terms of reducing $\mathrm{CO}_{2}$ emissions by almost $60 \%$ by 2050 , compared to 2013 and limiting the average global temperature increase to $2^{\circ} \mathrm{C}$ is currently not on track. Therefore, plans are being devised to address the technology-specific challenges in order to accelerate growth and improve policies for addressing the pre-development risks of geothermal energy.

The often cited technological (such as transmission and efficiency), socio-economic (including cost and politics), and environmental challenges towards the development and deployment of renewable energy forms are becoming achievable and cost-effective [4] [5]. In fact, as of the writing of this paper, unsubsidized solar and onshore wind are the cheapest sources of power in all major economies, based on a levelized cost of electricity assessment by Bloomberg New Energy Finance [6].

The objective of this research is the proposal of an alternative approach to clean, renewable geothermal energy use by means of geothermal groundwater pressure applied in a water turbine. The literature survey, does not show where a geothermal system operating with water pressure as opposed to water temperature has been proposed, employed or demonstrated, to the best of the authors knowledge. The water pressure from the candidate geothermal sites considered is applied to drive a water turbine for electrical energy generation. The considered geothermal candidate sites are low temperature, water-dominant sites, where it is not beneficial to apply low temperatures in a Rankine cycle (RC) steam turbine. Simple calculations are applied to estimate the electrical energy output of each candidate site. As a case study, the geothermal sites of tropical Nigeria are considered.

\section{Case Study-Nigeria}

The literature abounds with numerous studies on energy in Nigeria. This is partly owing to Nigeria being a well-endowed nation in terms of energy, as well as the poor state of the electrical energy available. Both renewable and non-renewable energy forms are significant, yet the electrical energy supply is very erratic. The lack of substantial generation and inadequate transmission infrastructure continue to be major issues. With a national population of 200 million (which is rapidly increasing), the electrical energy generation will need to increase exponentially. The electrical energy demand in Nigeria and much of Africa is increasing rapidly at present. The majority of the one billion inhabi- 
tants, of the African continent still lack electricity, and power outages are the norm. ICE electrical generators are also commonly used in households and businesses.

One of the greatest barriers of energy researchers in developing nations in general and Nigeria in particular, is insufficient data for engineers and scientists, among others. In the absence of robust data on energy, which may normally be available from responsible government agencies, researchers are left to work with the limited data that may be available. The amount of alternative, green, and environmentally advantageous energies that could be harvested in Nigeria and many other African nations is significant [7]. Almost all research studies on renewable energy in Nigeria have considered solar, hydropower, and wind resources [8] while other potentially significant alternative energy forms, such as tidal and geothermal energy [9] [10] [11] exist, for which research remains to be conducted to characterize their potentials effectively. While wind and solar may be the optimal readily exploitable renewable options in most African countries (including Nigeria), efforts must also be directed towards developing novel and perhaps local technologies to use other under-researched and unutilized renewable energy forms such as geothermal energy.

In Nigeria, geothermal resources are of low-quality heat, whereby conventional technologies such as the dry steam power generation system, single and double flash power generation system, and binary power generation system based on the Kalina cycle, Organic RC (ORC), or their combinations may not be efficient. However, as a major oil producing nation, it is possible that depleted and abandoned oil wells in Nigeria may also be retrofitted with an ORC by means of which the heat extracted from the oil well may be converted into electricity. To the best of the authors' knowledge, no such approach has yet been exploited in Nigeria. In [9], it was demonstrated that Nigeria includes 61 geothermal sites, with 48 being vapor-dominant, and 13 being water-dominant or springs. The average wellhead temperature is approximately $40^{\circ} \mathrm{C}$, and the temperature of the heat sink is $25^{\circ} \mathrm{C}$, similar to the annual mean air temperature in Nigeria. Several of these sites (such as Ikogosi Warm Springs and Wikki Warm Springs) mainly serve as tourist attractions. Furthermore, at Ikogosi Warm Springs, a site rich in culture and history, it consists of a mélange of warm (male) and a cold (female) springs that uniquely meets or intersects at a point without mixing, as the image in Figure 1 illustrates. This implies one can simultaneously dip both hands in the geofluid, at their intersection point and experience one side of the fluid to be warm and the other to be cold. The warm spring has five sources from where it ensues, one of which the image in Figure 2 shows. The source of the cold spring is, however, deep into the woodlands, and not easily reachable. For recreational purposes, the warm fluid is channeled through a pipe (without the use of a pump) to a swimming pool at the site used by tourists and locals. For health purposes, the cold fluid is consumed for the treatment of malaria, while the warm fluid is used for the treatment of skin ailments. 


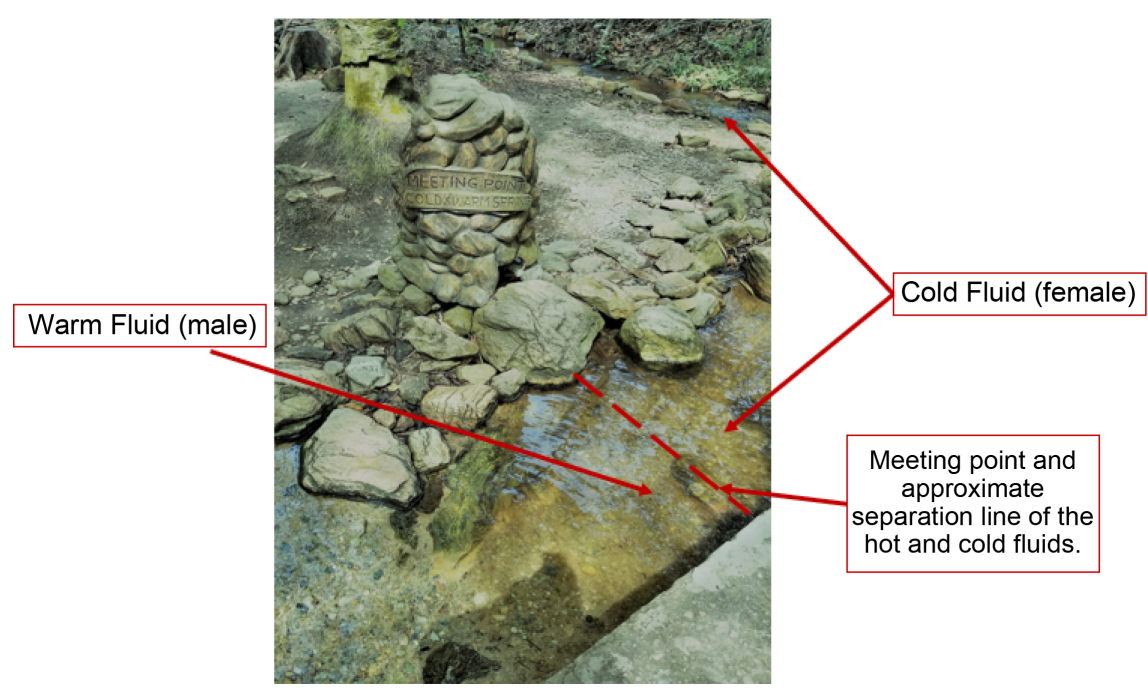

Figure 1. Meeting point of hot and cold fluids at Ikogosi Warm Springs.

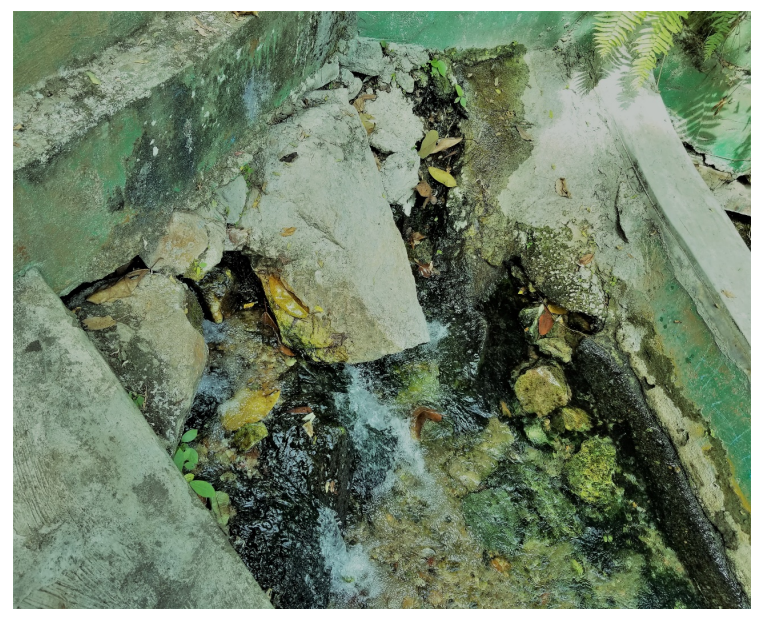

Figure 2. One of the five sources of the hot fluid at Ikogosi Warm Springs.

Additionally, it is understood that the waters at Ikogosi Warm Springs have been flowing in excess of 200 years. Otherwise, the geothermal springs are not being utilized for any other significant purpose. Nonetheless, the water is endlessly ensued from the sites, and as such, the water will remain available to continue to serve both its touristic and therapeutic purposes; however, it may also serve as an energy source.

Geothermal sites are dynamic systems that extend from depths of several meters to the surface. Based on the wellhead or surface temperatures, by applying the thermodynamic (exergy) method to estimate the geothermal resource potential, [9] demonstrated that the geothermal sites in Nigeria are low exergy or low-enthalpy sites. For example, a downhole exploration would produce detailed temperature/depth profiles for each site. As can be expected, downhole temperatures would be significant and, for example, could necessitate a revision of the estimates provided in [9]. If available, downhole measurements would reflect the 
actual reservoir conditions. As of this writing, the exploration and estimates provided by several researchers have been based on the computed heat flow from aeromagnetic spectral analysis. The average geothermal depth is conservatively approximately $3000 \mathrm{~m} \mathrm{[12].} \mathrm{Therefore,} \mathrm{it} \mathrm{can} \mathrm{be} \mathrm{concluded} \mathrm{that} \mathrm{the} \mathrm{data}$ currently available on the geothermal sites in Nigeria are insufficient. To the best of the authors' knowledge, downhole data is not available. In this work, we demonstrate that the wellhead temperature at the sites in Nigeria is insufficient for producing electrical energy in a cost-competitive manner. An alternative approach, as we discuss in Section 3, involves applying the water pressure to drive a conventional and off-the-shelf water turbine. This geothermal fluid is simply a carrier of energy.

However, technological advances have caused low-enthalpy geothermal energy to be popular and an attractive option for sustainable energy generation. Such advanced technologies include thermoelectric generators (TEGs) that may be applied to geothermal resource sites in Nigeria. The lower limit temperature for applying TEGs to electricity generation is $30^{\circ} \mathrm{C}$. TEG technology may be prohibitive for developing nations in the near term. However, such technology will bode well in the long-term for low enthalpy geothermal resource sites such as those in Nigeria, as the adoption of TEG increases and the associated costs decrease. At present, Nigeria does not have any geothermal power plants in operation or under development. However, efforts are being made to explore the geothermal resource potential fully for electrical energy generation [13] [14]. As climate change takes effect, economic problems and the social pressure for cleaner energy forms increases, engineers may have to be more creative in devising means for realizing the vast renewable energy resources of developing nations, such as Nigeria to a certain degree. Thus, considerable geothermal energy may, be available in the near term by using the geothermal ground water pressure applied in a water turbine from these sites, as opposed to the low temperatures. It is towards this task that this paper is directed.

\section{Energy Generation Analysis}

Several sites in the world have been ranked as low, medium, or high geothermal resources based on temperature, while others have been ranked using the exergy technique. Certain sites are vapor-dominant, while others are water-dominant. Many sites in the world possess significant temperatures to be applied in cycles and systems mentioned earlier for electricity production. Electrical energy generation in current competitive markets typically demands geothermal wellhead temperatures of over $135^{\circ} \mathrm{C}$, however, for direct use applications, this can be achieved economically with wellhead temperatures as low as $80^{\circ} \mathrm{C}$. Taken together, various sites in the world produce significant electrical energy, as mentioned in the introduction.

However, for low temperature or low enthalpy resources, particularly water-dominant sites or springs, insignificant energy may be available from the 
water heat, although the water pressure of most geothermal sites is, highly significant. Conventional applications for low-enthalpy resources would be providing thermal energy for district heating, supplying hot water residential and commercial buildings, and powering low-temperature industrial processes. Contrary to these conventional applications, in this section, an alternative approach is proposed. We use simple calculations to estimate the electrical energy output of geothermal resource sites whereby rather than using the heat of the water, the groundwater pressure is instead used directly to power a water turbine. Such a water turbine would be a typical off-the-shelf turbine, thus it will have low-cost implications. As a case study, the 13 known geothermal springs in tropical Nigeria are considered, as presented in Table 1. It should be remarked that, though not essential for this study, the temperature data in Table 1 is provided to give the reader some perspective of the resource and why an alternative approach is being proposed. The table also includes a column on well head pressure (WHP). As an example, images of the Ikogosi Warm Springs are provided in Figure 1 and Figure 2. A simple schematic of the geothermal water turbine system is illustrated in Figure 3. The reader will observe that the mathematical model is basic and simple. Thus, a rigorous refinement of the approach may be possible for future work whenever deep-well exploration data becomes available. Suffice to say that the model lacks rigor due to lack of sufficient data. The analysis is therefore simple enough for a first pass demonstration of the concept. The analysis considering water pressure is as follows.

The corresponding equations of the flow through a water turbine are given by the following expressions:

Table 1. Geothermal springs in Nigeria [9].

\begin{tabular}{cccc}
\hline No. & $\begin{array}{c}\text { Geothermal-hydrothermal sites } \\
(\text { springs or water-dominant } \\
\text { geothermal fields })\end{array}$ & Wellhead temperature $\left({ }^{\circ} \mathrm{C}\right)$ & WHP (MPa) \\
\hline 1 & Akiri Warm Saline Spring & 53.5 & 1.485 \\
2 & Awe 1 Flowing Saline Spring & 43.4 & 0.644 \\
3 & Awe 2 Warm Saline Spring & 38.6 & 0.895 \\
4 & Awe 3 Warm Saline Spring & 34.8 & 0.925 \\
5 & Keana Warm Saline Spring & 36.4 & 1.174 \\
6 & Azara Warm Fresh Water Spring & 33.4 & 0.705 \\
7 & Kanje Warm Fresh Water Spring & 33.4 & 1.112 \\
8 & Ribi Warm Saline Spring & 34.2 & 1.324 \\
9 & Ikogosi Warm Springs & 37 & 1.644 \\
10 & Ruwan Zafi Springs & 54 & 1.432 \\
11 & Wikki Warm Springs & 32 & 1.865 \\
12 & Igbonla Springs & $51($ average $)$ & 1.985 \\
13 & Rafin Reewa Warm Spring & 42 & 1.155 \\
\hline
\end{tabular}




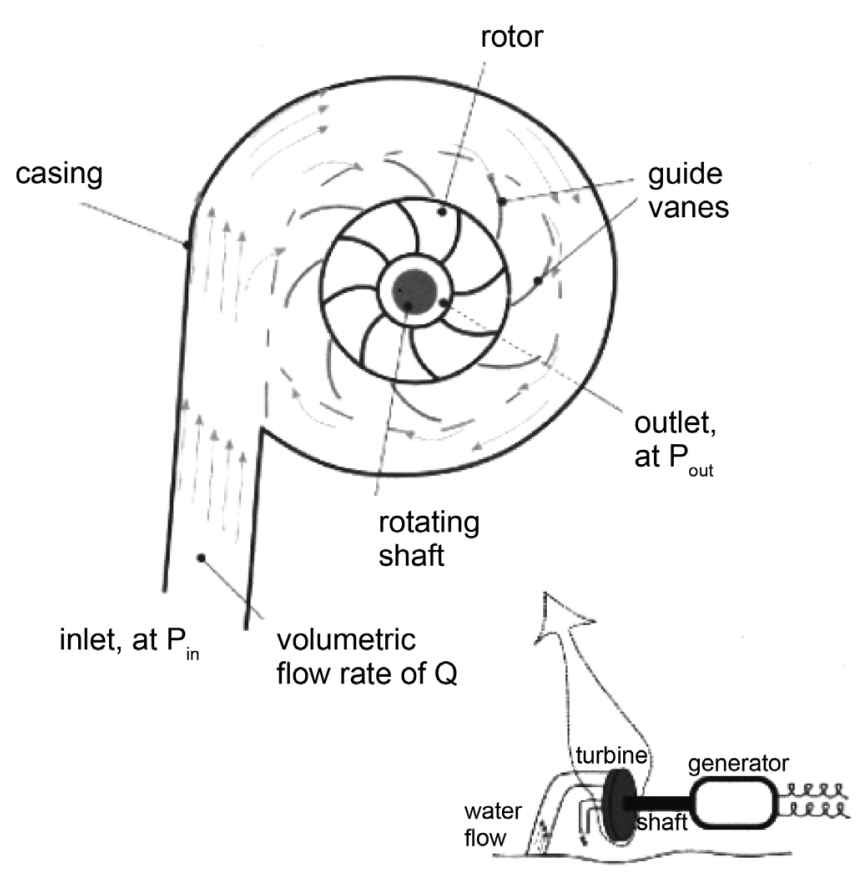

Figure 3. Diagrammatic sketch of electrical energy generation using geothermal water driven by water turbine.

$$
\begin{gathered}
\text { Fluid Power, } \dot{W}_{\text {fluid }}=\left(\Delta P \equiv P_{\text {in }}-P_{\text {out }}\right) \times Q \\
\text { Shaft Power, } \dot{W}_{\text {shaft }}=\tau \times \omega \\
\text { Turbine efficiency, } \eta=\frac{\dot{W}_{\text {shaft }}}{\dot{W}_{\text {fluid }}}
\end{gathered}
$$

where $\Delta P$ in Equation (1) is the pressure drop, and $Q$ is the volumetric flow rate. For example, using a wellhead pressure of $1.485 \mathrm{MPa}$ (Akiri Warm Saline Spring from Table 1), an atmospheric pressure of $0.1 \mathrm{MPa}$, and the corresponding mass flow rate of approximately $200 \mathrm{~L} / \mathrm{s}$, we obtain the following using Equation (1),

$$
\begin{aligned}
P= & \left(1.485 \times 10^{6} \mathrm{~N} / \mathrm{m}^{2}-0.1 \times 10^{6} \mathrm{~N} / \mathrm{m}^{2}\right) \\
& \times 200 \mathrm{~L} / \mathrm{s} \times 0.001 \mathrm{~m}^{3} / \mathrm{L} \times 0.001 \mathrm{~kW} /(\mathrm{N} \cdot \mathrm{m} / \mathrm{s}) \\
= & 277 \mathrm{~kW}
\end{aligned}
$$

While mass flow rates will vary according to the selected site, the mass flow rate of $200 \mathrm{l} / \mathrm{s}$ used is a conservative estimate for locations in Nigeria, based on the authors visits to some sites. Mass flow rates for some other sites in the world are presented in Table 2. The output value of $277 \mathrm{~kW}$ is the fluid power. To obtain the shaft power, we must multiply this value by the turbine efficiency. Although, the water turbine efficiency varies significantly, we assume $85 \%$ for commercial water turbines according to [15] [16]. However, other work suggested substantially lower values for small turbines, low pressure or low flow rates [17]. Using $85 \%$, we obtain a value of $235 \mathrm{~kW}$ available as the shaft power. Of course, further efficiencies would be involved in using a generator to obtain electricity. 
Table 2. Mass flow rates of some geothermal sites in the world [20].

\begin{tabular}{cc}
\hline Plant/Location & Resource mass flow rate (liters/sec) \\
\hline Amedee, USA & 205 \\
Wineagle, USA & 63 \\
Altheim, Austria & 86 \\
Otake, Japan & 14.66 \\
Nigorikawa, Japan & 50 \\
Reno, NV, USA & 556 \\
\hline
\end{tabular}

\section{Results and Discussion}

The results of the analysis for all of the water-dominant sites displayed in Table 1 are presented in Table 3, to include two columns on fluid power (kW) and shaft power $(\mathrm{kW})$. Table 3 is subsequently recast graphically as shown in Figure 4 , with the results of the electrical energy generation potential. In summary, 2.5 MW may be available using geothermal water pressure, which is more significant than if geothermal temperature was used.

If we considered using temperature to generate electricity, the power output would generally be insignificant (approximately $5 \mathrm{~kW}$ ) for average wellhead temperatures of $40^{\circ} \mathrm{C}$, if the total temperature $\operatorname{drop}\left(40^{\circ} \mathrm{C}\right.$ to $\left.25^{\circ} \mathrm{C}\right)$ was divided evenly between the hot side heat exchanger, the cold side heat exchanger, and heat engine, and if a heat engine could be designed so that it would produce $25 \%$ of the maximum possible efficiency. In this case, the heat exchangers would have to be enormous, and the heat engine would have to be extraordinarily well designed and custom built with minimal losses, while the water turbine would be an off-the-shelf component. At these temperatures, the Carnot efficiency (theoretical limit) would also be very low, at less than $10 \%$. This indicates that, at the theoretical limit, one would have to move approximately 21 times as much heat as we would get out in electricity. In the real world, an extremely well-designed system may produce 1/4-1/3 of the Carnot efficiency. This further means moving over 60 times as much heat as one would obtain in electricity. Thus, why are we concerned with the efficiency if the heat (geothermal) is, in principle, free? This is because, firstly, efficiency is a key parameter for electrical power generation, and secondly, owing to the capital costs. Moving a substantial amount of heat requires large (expensive) heat exchangers, pipes, and pumps, among other equipment. A system that provides, for example, with US $\$ 1000$ per year in "free" electricity may sound good, but if it costs US \$1 million to build, it will deter investors. Therefore, so little energy is available from the heat of the water that it may be preferable to ignore the heat entirely and use the pressure to directly power a water turbine.

Based on the brief analysis presented in this research, it remains very questionable as to how, in other works, the geothermal resource potential in Nigeria was estimated to be $500 \mathrm{MW}$ [13] [14]. This is, at best, a lofty and faulty estimate, 
Table 3. Energy generation analysis output.

\begin{tabular}{cccccc}
\hline No. & $\begin{array}{c}\text { Geothermal-hydrothermal } \\
\text { sites (springs or } \\
\text { water-dominant } \\
\text { geothermal fields) }\end{array}$ & $\begin{array}{c}\text { Wellhead } \\
\text { temperature } \\
\left({ }^{\circ} \mathrm{C}\right)\end{array}$ & $\begin{array}{c}\text { WHP } \\
(\mathrm{MPa})\end{array}$ & $\begin{array}{c}\text { Fluid power } \\
(\mathrm{kW})\end{array}$ & $\begin{array}{c}\text { Shaft power } \\
(\mathrm{kW})\end{array}$ \\
\hline 1 & Akiri Warm Saline Spring & 53.5 & 1.485 & 277 & 235.45 \\
2 & Awe 1 Flowing Saline Spring & 43.4 & 0.644 & 108.8 & 92.48 \\
3 & Awe 2 Warm Saline Spring & 38.6 & 0.895 & 159 & 135.15 \\
4 & Awe 3 Warm Saline Spring & 34.8 & 0.925 & 165 & 140.25 \\
5 & Keana Warm Saline Spring & 36.4 & 1.174 & 214.8 & 182.58 \\
6 & Azara Warm Fresh Water Spring & 33.4 & 0.705 & 121 & 102.85 \\
7 & Kanje Warm Fresh Water Spring & 33.4 & 1.112 & 202.4 & 172.04 \\
8 & Ribi Warm Saline Spring & 34.2 & 1.324 & 244.8 & 208.08 \\
9 & Ikogosi Warm Springs & 37 & 1.644 & 308.8 & 262.48 \\
10 & Ruwan Zafi Springs & 54 & 1.432 & 266.4 & 226.44 \\
11 & Wikki Warm Springs & 32 & 1.865 & 353 & 300.05 \\
12 & Igbonla Springs & $51($ average) & 1.985 & 377 & 320.45 \\
13 & Rafin Reewa Warm Spring & 42 & 1.155 & 211 & 179.35 \\
& & & & & 2557.65 \\
\hline
\end{tabular}

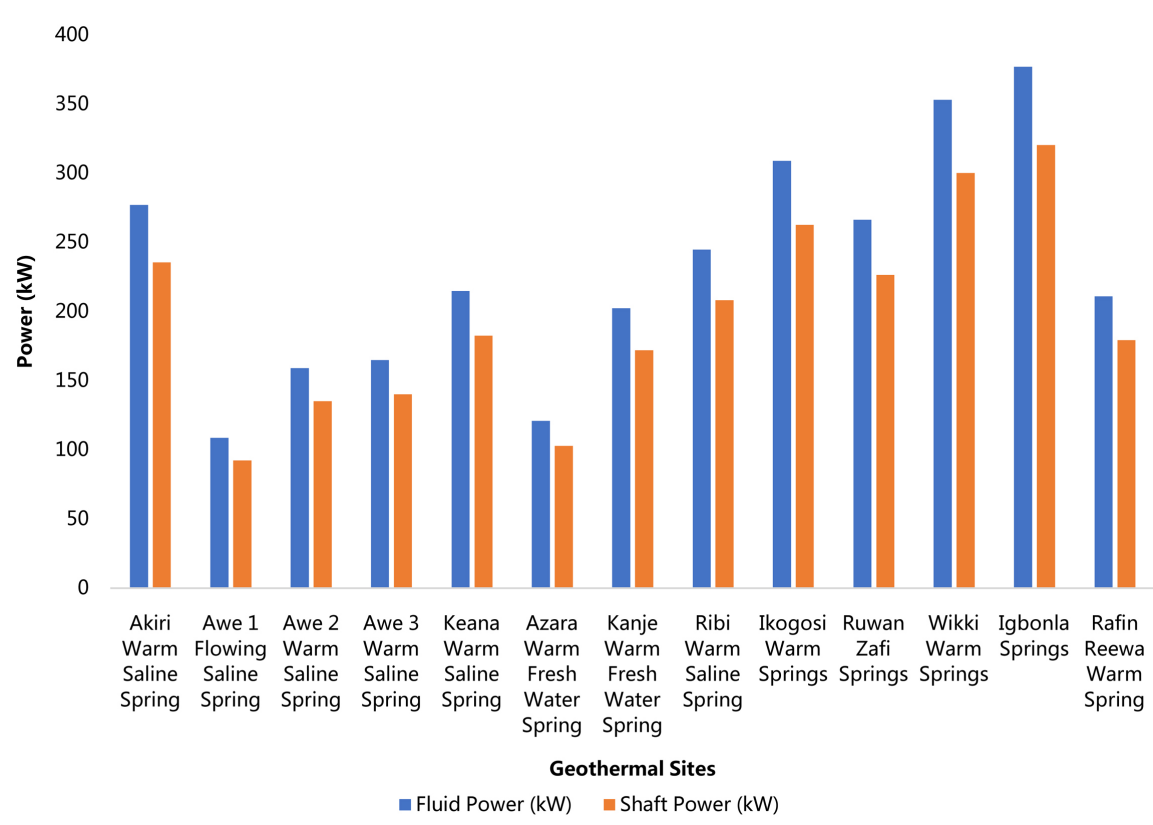

Figure 4. Fluid and shaft power output from geothermal spring sites.

as the authors did not clearly express or provide any analysis to demonstrate the manner in which they arrived at such an estimate. Furthermore, as there have been no known downhole geothermal explorations and data for the various sites in Nigeria, it is perhaps impossible to fully ascertain a $500 \mathrm{MW}$ estimate, particularly an estimate based on temperature [18]. In fact, in [19], and buttressing the work of [9], it was determined that parts of the Niger Delta Basin, in which sig- 
nificant oil and gas drilling has occurred, has heat flow values of less than 100 $\mathrm{mW} / \mathrm{m}^{2}$ (100 $\mathrm{mW} / \mathrm{m}^{2}$ being the minimum standard for a viable geothermal source). This estimate suggests that the basin may not be viable as a geothermal source. It is also notable that approximately $135^{\circ} \mathrm{C}$ is the minimum adequate temperature for electrical energy generation using geothermal heat [18].

Therefore, instead of harvesting heat from the fluid and using it in a steam turbine, the wellhead water pressure is applied in a water turbine to generate electrical energy. The wellhead pressure supplies water at these pressures and can be passed through a water turbine. In doing so, substantially more electrical energy could be generated by ignoring the water heat and using the water pressure to turn a water turbine. The water from these geothermal candidate sites serves as a renewable resource that can be used to produce electricity to power rural and local environs directly, or transmitted to the grid. The conversion efficiency and cost implications are the greatest limitations in geothermal energy utilization, particularly for low to medium temperature resources. These limitations result in geothermal energy being less competitive than other forms of power generation, such as natural gas. In summary, the analysis presented in this study may also be applied to other low-enthalpy geothermal springs in the world.

\section{Conclusions and Recommendations}

In the preceding sections, a simple, non-rigorous alternative approach to using low-enthalpy geothermal resources for electrical energy generation has been discussed. Very simple thermodynamic calculations and analyses have been applied to demonstrate the energy generation potential from the considered candidate sites. This simple analysis has focused on utilizing the low-enthalpy geothermal resources for electrical energy generation from selected sites for a generalized geothermal resource assessment. Harnessing the geothermal resources using the approach proposed in this research can, at the very least, provide local solutions for increasing energy needs. The use of the water heat, which is the conventional approach for using geothermal energy, has been determined insufficient, based on the available wellhead temperature data. Moreover, the energy produced by applying water pressure in a water turbine is shown to be more significant. The approach may further be developed in-depth and applied to other regions of the world. The following specific conclusions may be drawn.

1) So little energy is available from the water heat that it may be preferable to ignore the heat entirely and use the water pressure to directly power a water turbine.

2) The total estimated power generation from the geothermal springs using a water turbine is approximately $2.5 \mathrm{MW}$.

3) The utilization of geothermal water could meet near-term energy demands, particularly in rural and remote areas that are mostly without grid electricity.

4) There remains insufficient involvement, assessment, and planning towards 
renewable energy forms in Nigeria, particularly geothermal energy.

5) For more current knowledge on the geothermal energy potential of Nigeria, a database of the temperatures recorded at the bottom of several holes, together with a related and detailed local investigation, is highly important and necessary. The highest quality of geothermal data can only be obtained from extended downhole temperature readings collected in several wells that are in thermal equilibrium. This approach would better aid the resource characterization.

6) Downhole exploration would establish realistic conditions that may be applied for determining the optimal working parameters (such as the mass flow rate).

7) Significant research and a thorough assessment of all renewable energy options remain crucial to provide a robust and sustainable energy sector. Although Nigeria remains a major oil-and-gas-producing nation, vast and underdeveloped renewable energy forms exist as alternatives within her shores.

8) The analysis presented in this study may also be applied to other low-enthalpy geothermal springs in the world.

The problem of developing an alternative approach to utilizing low-enthalpy geothermal springs for electrical energy generation has been investigated using simple thermodynamic calculations. In the future, vigorous engineering efforts must be directed towards determining means to fully utilize low-enthalpy renewable geothermal energy resources. Geothermal energy offers the potential to significantly contribute to driving developing nations, such as Nigeria, towards a more diversified and sustainable energy system and future. It is envisaged that this research may inject a much-needed impetus and accelerate the development and uptake of geothermal energy, which is a significant but largely unutilized constant renewable energy resource.

\section{Conflicts of Interest}

The author declares no conflicts of interest regarding the publication of this paper.

\section{References}

[1] Farquharson, D., Jaramillo, P. and Samaras, C. (2018) Sustainability Implications of Electricity Outages in Sub-Saharan Africa. Nature Sustainability, 1, 589-597. https://doi.org/10.1038/s41893-018-0151-8

[2] Olowosejeje, S.A. (2019) Nigeria's Unreliable Electricity Costs Its Economy \$29 Billion a Year-Solar Power Would Save Billions. https://qz.com/africa/1632978/nigeria-solar-power-could-fix-costly-electricity-prob lems/

[3] REN21 Renewable Energy Policy Network for the 21st Century (2011) Renewables 2011 Global Status Report. REN21 Secretariat, Paris. http://www.ren21.net/Portals/97/documents/GSR/REN21_GSR2011.pdf

[4] Wu, G.C., et al. (2017) Strategic Siting and Regional Grid Interconnections Key to Low-Carbon Futures in African Countries. Proceedings of the National Academy of Sciences of the United States of America, 114, E3004-E3012. 
https://doi.org/10.1073/pnas.1611845114

[5] Li, Y., et al. (2018) Climate Model Shows Large-Scale Wind and Solar Farms in the Sahara Increase Rain and Vegetation. Science, 361, 1019-1022.

https://doi.org/10.1126/science.aar5629

[6] Bloomberg New Energy Outlook 2018. https://bnef.turtl.co/story/neo2018?teaser=true

[7] International Renewable Energy Agency (IRENA), Renewable Capacity Statistics 2018. https://www.irena.org/-/media/Files/IRENA/Agency/Publication/2018/Mar/IRENA _RE_Capacity_Statistics_2018.pdf

[8] Oyedepo, S.O., et al. (2008) Towards a Sustainable Electricity Supply in Nigeria: The Role of Decentralized Renewable Energy System. European Journal of Sustainable Development Research, 2, Article No. 40. https://doi.org/10.20897/ejosdr/3908

[9] Amoo, O.M.A. (2014) Thermodynamic Based Resource Classification of Geothermal Energy in Nigeria. Journal of Renewable and Sustainable Energy, 6, Article ID: 033129. https://doi.org/10.1063/1.4881687

[10] Amoo, L.M. (2018) Aperiodic Tidal Data Resource Assessment and LCOE Analysis of Selected Areas in Nigeria. Clean Energy, 2, 45-57. https://doi.org/10.1093/ce/zky007

[11] Amoo, L.M. (2018) Techno-Economic Assessment of Energy Production Potential from Tidal Streams in Nigeria. International Journal of Energy and Environmental Engineering, 9, 81-98. https://doi.org/10.1007/s40095-017-0256-2

[12] Falcone, G., Liu, X., Okech, R.R., Seyidov, F. and Teodoriu, C. (2018) Assessment of Deep Geothermal Energy Exploitation Methods: The Need for Novel Single-Well Solutions. Energy, 160, 54-63. https://doi.org/10.1016/j.energy.2018.06.144

[13] Olaoye, T., Ajilore, T., Akinluwade, K., Omole, F. and Adetunji, A. (2016) Energy Crisis in Nigeria: Need for Renewable Energy Mix. American Journal of Electrical and Electronic Engineering, 4, 1-8.

[14] Abraham, E.M. and Nkitnam, E.E. (2017) Review of Geothermal Energy Research in Nigeria: The Geo-Science Front. International Journal of Earth Science and Geophysics, 3, 15. https://doi.org/10.35840/2631-5033/1815

[15] https://www.renewablesfirst.co.uk/hydropower/hydropower-learning-centre/howmuch-power-couldi-generate-from-a-hydro-turbine/

[16] https://www.mpoweruk.com/hydro_power.htm

[17] Sritram, P. and Suntivarakorn, R. (2017) Comparative Study of Small Hydropower Turbine Efficiency at Low Head Water. Energy Procedia, 138, 646-650.

https://doi.org/10.1016/j.egypro.2017.10.181

[18] Brimmo, A.T., Sodiq, A., Sofela, S. and Kolo, I. (2017) Sustainable Energy Development in Nigeria: Wind, Hydropower, Geothermal and Nuclear (Vol. 1). Renewable and Sustainable Energy Reviews, 74, 474-490. https://doi.org/10.1016/j.rser.2016.11.162

[19] Chukwu, C.G., Udensi, E.E., Abraham, E.M., Ekwe, A.C. and Selemo, A.O. (2018) Geothermal Energy Potential from Analysis of Aeromagnetic Data of Part of the Niger-Delta Basin, Southern Nigeria. Energy, 143, 846-853. https://doi.org/10.1016/j.energy.2017.11.040

[20] Tchanche, B.F., Lambrinos, G., Frangoudakis, A. and Papadakis, G. (2011) LowGrade Heat Conversion into Power Using Organic Rankine Cycles-A Review of Various Applications. Renewable and Sustainable Energy Reviews, 15, 3963-3979. https://doi.org/10.1016/j.rser.2011.07.024 